
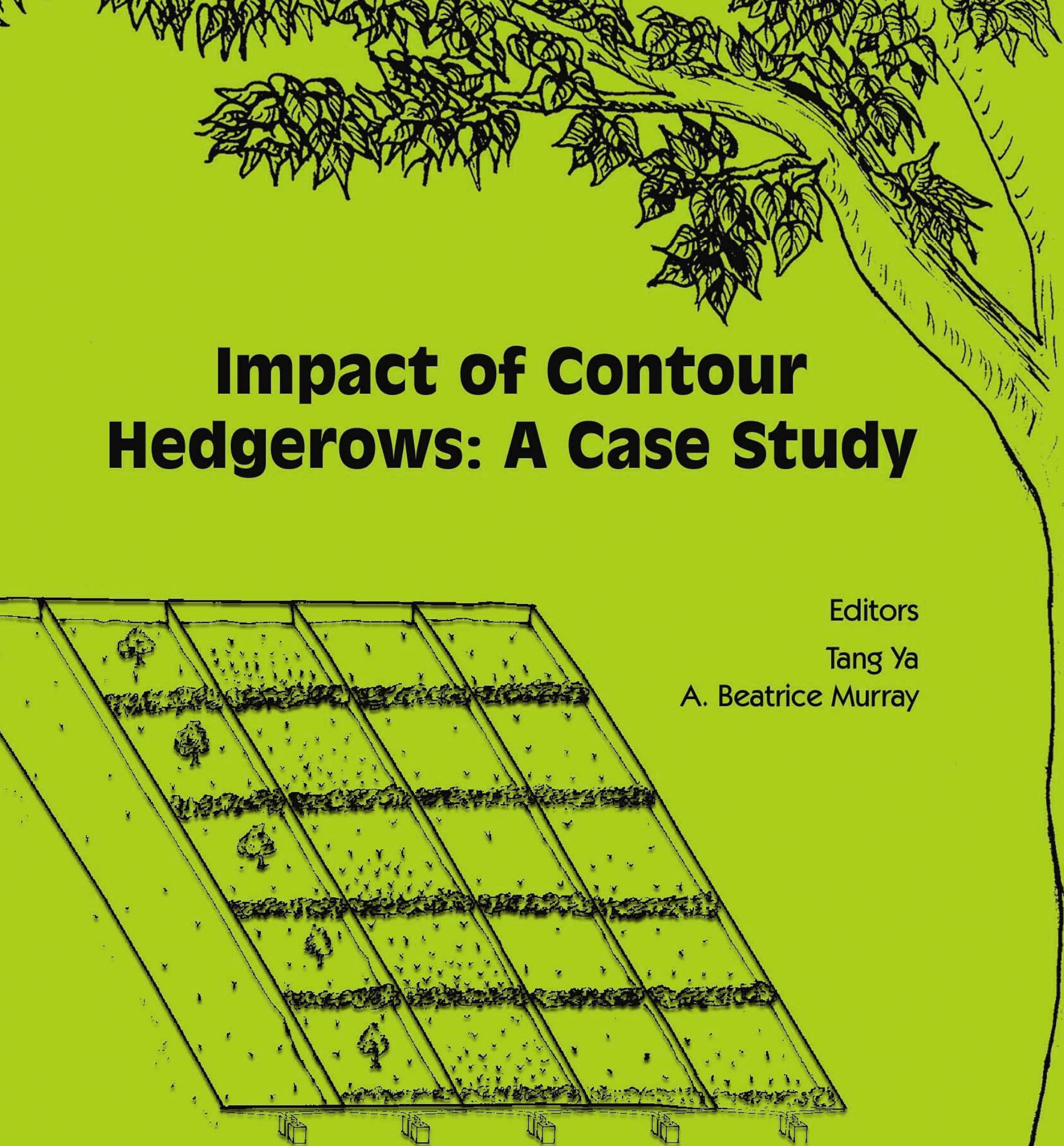

Editors

Tang Ya

rof

(

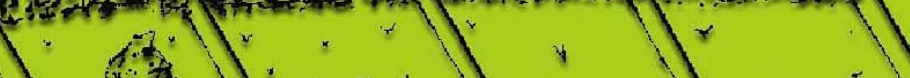

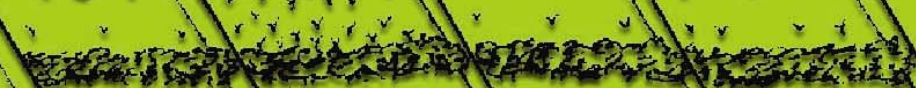

$(x, y)+y=$

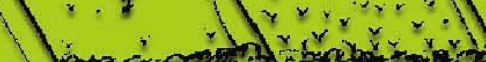

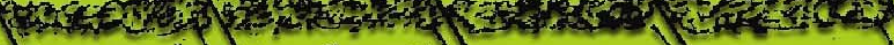

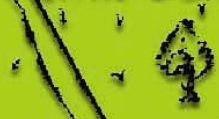

di

$\sqrt{i 0}$

(4)

Focus or 


\section{About ICIMOD}

The International Centre for Integrated Mountain Development (ICIMOD) is an independent 'Mountain Learning and Knowledge Centre' serving the eight

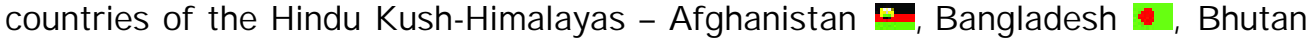

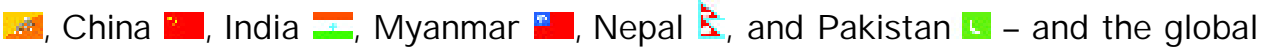
mountain community. Founded in 1983, ICIMOD is based in Kathmandu, Nepal, and brings together a partnership of regional member countries, partner institutions, and donors with a commitment for development action to secure a better future for the people and environment of the Hindu Kush-Himalayas. The primary objective of the Centre is to promote the development of an economically and environmentally sound mountain ecosystem and to improve the living standards of mountain populations.

\section{Focus on Godavari}

The series 'Focus on Godavari' will feature information on topics related to the activities of the ICIMOD Demonstration and Training Centre, Godavari. The topics will include background information about technologies, species, and general approaches for integrated mountain development; results of trials and recommendations of appropriate species and technologies; and reports on outreach and training activities both on and off site.

\section{Available titles (December 2004)}

\#1 Seeing is Believing: the ICIMOD Demonstration and Training Centre, Godavari (forthcoming)

\#2 Nature's Bounty: Nitrogen-Fixing Plants for Mountain Farmers

\#3 Impact of Contour Hedgerows: A Case Study

\#4 Performance and Selection of Nitrogen-Fixing Hedgerow Species

\#5 Perennial Cash Crops for Mountain Areas (forthcoming) 


\title{
Impact of Contour Hedgerows A Case Study
}

\author{
Editors \\ Tang Ya \\ A. Beatrice Murray
}

Focus on Godavari \#3

Intemational Centre for Integrated Mouna in Development Natural Resources Management Programme Kathmandu, Nepal

November2004 


\section{Copyright @ 2004}

International Centre for Integrated Mountain Development

All rights reserved

\section{Credits}

Photos by A. Beatrice Murray, ?????

Sketches by Asha Kaji Thaku

Cover design concept Sanjay Madnani

\section{Published by}

International Centre for Integrated Mountain Development

G.P.O. Box 3226

Kathmandu, Nepal

\section{ISBN 9291159581}

\section{Editorial Team}

A.Beatrice Murray (Editor)

Dharma R. Maharjan (Technical Support and Layout Design)

\section{Printed and bound in Nepal by}

Quality Printers Pvt. Ltd., Kathmandu, Nepal

The views and interpretations in this paper are those of the contributor(s). They are not attributable to the International Centre for Integrated Mountain Development (ICIMOD) and do not imply the expression of any opinion concerning the legal status of any country, territory, city or area of its authorities, or concerning the delimitation of its frontiers or boundaries, or the endorsement of any product. 


\section{Forew ord \\ Focus on Godavari}

The International Centre for Integrated Mountain Development (ICIMOD) was established in 1983 amidst increasing concern about environmental degradation and poverty in the Hindu Kush-Himalayan (HKH) region. Its area of mandate is the Hindu Kush-Himalayan region (all or part of the eight countries Afghanistan, Bangladesh, Bhutan, China, India, Myanmar, Nepal, and Pakistan). ICIMOD's activities focus on the reduction of poverty and the conservation of the natural resource base.

The HKH sustains a population of about 150 million peoples of diverse cultures, the great majority of whom depend upon agriculture as their main source of livelihood. The well-being of mountain peoples is to a great extent determined by the state of mountain agriculture and the potential for economic improvement. Equally, the security of the livelihoods of future generations depends on ensuring that use of natural resources is sustainable, and that the environment is maintained and not degraded.

Mountain agriculture in the $\mathrm{HKH}$ is slowly transforming from traditional farming of cereal crops to mixed farming of high-value cash crops and animal husbandry for income. This agricultural transformation poses new challenges, and farmers can no longer rely solely on the wealth of indigenous knowledge acquired over generations. New choices of appropriate crops for the specific local mountain conditions, choices of appropriate methods for land use intensification without upsetting the sensitive balance of fragile mountain ecosystems, new methods of extending agricultural practices to marginal lands that stabilise rather than destroy, increasing the water supply through water harvesting and irrigation, new ways of improving crop productivity and quality without negatively affecting the environment, are technologies that must be tried, tested and integrated within existing farming systems. Many improved technologies have been developed for and promoted in mountain areas with the aim of reducing poverty and conserving the environment. But as mountain farmers have very limited resources, they are risk adverse and will not invest in an improved technology unless they can assess it carefully first. For technologies to be adopted by farmers they must first be tested and demonstrated in an accessible and convincing way.

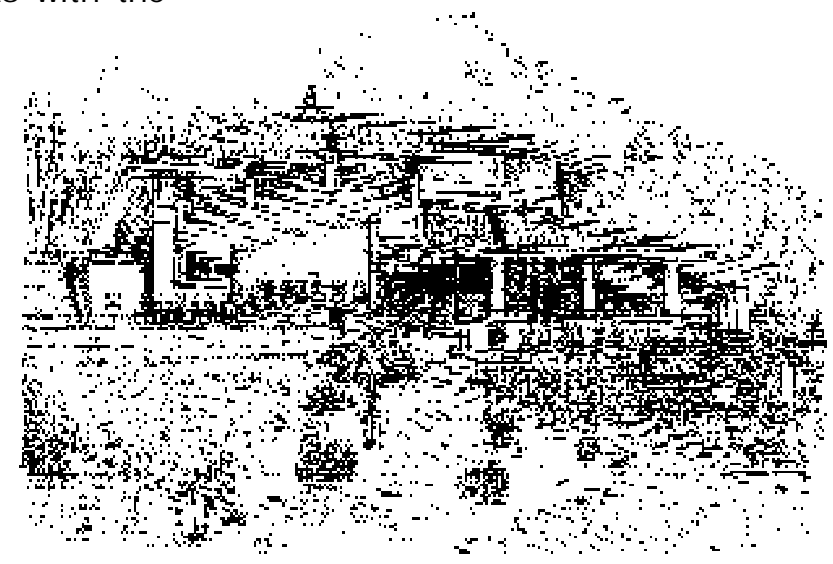


ICIMOD established its Demonstration and Training Centre at Godavari, on the southern slopes of the Kathmandu Valley, in March 1993, following the generous provision of 35 hectares of land by His Majesty's Government of Nepal in November 1992. The site provides a place where different technologies and (farming) practices useful for sustainable development can be tested, selected, and demonstrated; where farmers and those who work with them can be trained; and which can serve as a repository for plant germplasm resources and associated floral and faunal biodiversity. Activities in an integrated agricultural system are by their nature cross-cutting and often interactive and interdependent. The activities at the Godavari Centre are linked within a holistic approach that covers a broad range of the possibilities for livelihood - and quality of life improvement of mountain farmers.

Over the years a large amount of information has been accumulated related to the activities at the Godavari Centre. It includes background information about technologies, species, and general approaches for integrated mountain development; results of trials and recommendations of appropriate species and technologies; training materials; and many others. The series 'Focus on Godavari' has been developed to provide a platform for formal publication and wider dissemination of this information. We hope that these books will prove useful to a wide audience, and help provide information that will benefit mountain farmers. We welcome feedback from our readers and new ideas for the series.

J. Gabriel Campbell

Director General, ICIMOD 


\title{
Preface
}

Severe soil erosion and declining soil fertility are widely regarded as major problems threatening the sustainable use of sloping agricultural land in the Hindu KushHimalayan region. Each year, large amounts of soil are lost from sloping land in the Hindu Kush-Himalayan (HKH) region, mainly as a result of water erosion. One of the most effective ways that farmers have found to increase the stability and workability of sloping cropland has been to build terraces, but traditional terracing does not always prevent land degradation, especially when extended to steeper slopes and more marginal land. Sloping agricultural land technology (SALT), also known as contour hedgerow intercropping (agroforestry) technology (CHIAT), was developed some twenty years ago as a new approach that combines the strengths of terracing with the strengths of natural vegetation to stabilise sloping land and make it available for farming. In this system, dense hedgerows of fast growing perennial woody tree or shrub species, usually nitrogen-fixing species, are planted along contour lines to create a living barrier that traps sediments and gradually transforms the sloping land to terraced land. When successful, the technique simultaneously reduces soil erosion and improves soil fertility.

SALT or CHIAT was originally developed for use in tropical countries. In the early nineteen-nineties, ICIMOD, in collaboration with a number of national institutions, introduced the contour hedgerow technology to six countries in the Hindu KushHimalayas to assess its feasibility in the region, mostly under the project on Appropriate Technologies for Soil Conserving Farming Systems funded by the Asian Development Bank. Two experiments were set up at ICIMOD's Trial and Demonstration site at Godavari to investigate different aspects of SALT and its usefulness and applicability in the cooler climate of the Himalayan mid-hills. The studies showed clearly that SALT can be used effectively in subtropical and temperate regions, not only in the tropical regions where it was first developed. The method can help facilitate sustainable management of sloping cropland and contribute to sustainable mountain agricultural development and environmental conservation by reducing soil erosion and increasing productivity, opening up the possibility of continuous cultivation of sloping croplands.

This book describes the experiments, and their results and implications. I hope it will prove useful for farmers and development workers considering using SALT to slow degradation and increase the productivity of sloping land, and also provide an incentive for the increased application of this approach in the HKH region. Many of the plots established for these trials are still being used to demonstrate the technology and can be viewed at ICIMOD's Demonstration and Training Centre at Godavari. They provide a convincing example of the potential value of the approach.

\author{
Eklabya Sharma \\ Programme Manager \\ Integrated Programme on \\ Natural Resource Management
}




\section{Executive Summary}

Severe soil erosion and declining soil fertility are widely regarded as major problems threatening the sustainable use of sloping agricultural land in the Hindu KushHimalayan region. Simple terracing is widely used to control soil erosion, but it is not always effective and increasingly less so as agriculture is extended to ever more and steeper slopes in the attempt to increase production. There are few effective methods available in the region to control soil erosion and improve soil fertility simultaneously. Sloping agricultural land technology (SALT), or contour hedgerow intercropping (agroforestry) technology (CHIAT), using nitrogen-fixing plants has shown potential in tropical regions in controlling soil erosion and in improving soil fertility of sloping agricultural land. In this system, the terraces are developed by planting dense hedgerows of fast growing perennial woody tree or shrub species, usually nitrogen-fixing species, along contour lines thus creating a living barrier that traps sediments and gradually transforms the sloping land to terraced land. The hedgerows lining the terrace help improve soil fertility through nitrogen fixation at the roots and incorporation of the hedgerow trimmings into the soil. However, competition is sometimes observed between the hedgerows and the crops in the alleys; fear of this is thought to have inhibited widespread adoption of the technology by farmers in tropical regions.

Two experiments were set up at ICIMOD's Trial and Demonstration site at Godavari to investigate different aspects of SALT and its usefulness and applicability in the cooler climate of the Himalayan mid-hills. The first experiment, from 1995 to 2001, investigated the impact of hedgerows on soil erosion and soil fertility; the second, from 1998-2001, looked at the potential competition between hedgerows and crops for soil nutrients and soil moisture. The results of these experiments are described in this book: Chapter 1 provides an overview of SALT and the experimental set up at the Godavari site; Chapter 2 describes the impact of hedgerows on soil erosion; Chapter 3 the impact of hedgerows on soil fertilty; Chapter 4 the extent of hedgerowcrop competition for nutrients; and Chapter 5 the extent of hedgerow-crop competition for soil moisture.

The impact of hedgerows on soil erosion and soil fertility was tested using five different treatments: one with normal farming practice without hedgerows, and four with two different hedgerow species, different cropping approaches, and with or without application of organic fertiliser for the annual crops.

Soil erosion was evaluated from sediment concentration in runoff and total runoff. The contour hedgerows were very effective in reducing soil erosion to a very low level, with a marked impact from the second year of planting and a reduction in soil loss by $80-99 \%$ from the fifth year on, suggesting that hedgerows have the potential to facilitate continuous cultivation of sloping cropland. 
Soil fertility was monitored through annual collection and analysis of soil samples from a depth of $0-30 \mathrm{~cm}$. The hedgerows did not improve soil fertility in the experiments with freshly planted hedgerows as evaluated in terms of parameters like organic matter and nitrogen. This was partly because the soils started with a high level of most soil nutrients in a fertile forest soil, rather than a degraded agricultural soil, and partly because of the low production of fresh biomass by the hedgerows. The hedgerows did help reduce loss of available potassium and in the long run would probably help maintain soil fertility. One type of land use management, planting of peach trees in the alleys with intercropping of vegetables, did increase the availability of several nutrients, especially available phosphorous and potassium.

Hedgerow-crop competition for nutrients and soil moisture was assessed using sample sites with or without cultivation of crops in an established hedgerow alley. Soil samples were collected at three different distances from hedgerows and analysed for soil nutrients. Soil moisture was assessed from measurements at five-day intervals of soil tension at four different depths at each of three different distances from the hedgerows. The potential competition for water between hedgerow and crop was investigated by modelling.

The results indicate that there was no competition between hedgerows and crops for soil nutrients; the soil content of most nutrients was higher closer to the hedgerows suggesting that the hedgerows actually improved the soil nutrient status. There was competition between the hedgerows and crops for soil moisture in the dry season. Interestingly, although yield of radish (the dry season crop) was higher closer to the hedgerows, yield of maize (the monsoon crop) was slightly lower, indicating that factors other than nutrient status affect crop yield, and that the effects on different crops are not uniform.

The study showed clearly that SALT can be used effectively in subtropical and temperate regions, not only in the tropical regions where it was first developed. The method can help facilitate sustainable management of sloping cropland and can contribute to sustainable mountain agricultural development and environmental conservation by reducing soil erosion and increasing productivity, opening up the possibility of continuous cultivation of sloping croplands. In order for the technology to achieve its full potential, other, possibly more appropriate, hedgerow species need to be tested, and more investigations of different crops and their yields need to be carried out to identify optimum combinations for applications in temperate and subtropical areas of the $\mathrm{HKH}$. 


\section{Acknowledgements}

The authors would like to thank Dr. Tej Partap, former Head Mountain Farming Systems Division, ICIMOD, for his continued support; the Asian Development Bank for financial support to the project on Appropriate Technologies for Soil Conserving Farming Systems, under which much of this research was undertaken; Mr. Suraj B. Thapa, Farm Manager for generous assistance and support; Mr. Jivan Tamang for field data collection; Mr. Prabakhar B. Shah for arranging the chemical analysis of the soil samples collected from 1995 to 1997; Dr. Zhang Bin and Mr. Zong Haihong of the Nanjing Institute of Soil Science, Chinese Academy of Sciences, for chemical analysis of the soil samples collected in 1998-2001 and for assisting in the design of the experiments on competition and analysis of soil samples, and Dr. Sun Hui of the College of Environment, Sichuan University, for statistical analysis. We thank Mr. Dharma R. Maharjan of ICIMOD's Publications Unit for the preparation of figures and the layout design of this publication.

\section{Acronyms and Abbreviations}

ATSCFS Appropriate Technologies for Soil Conserving Farming Systems

CEC cation exchange capacity

CHIAT contour hedgerow intercropping (agroforestry) technology

ECEC effective cation exchange capacity

$\mathrm{HKH} \quad$ Hindu Kush-Himalaya(s/n)

HYV high yielding variety

IBSRAM International Board for Soil Research and Management

ICIMOD International Centre for Integrated Mountain Development

SALT Sloping agricultural land technology 


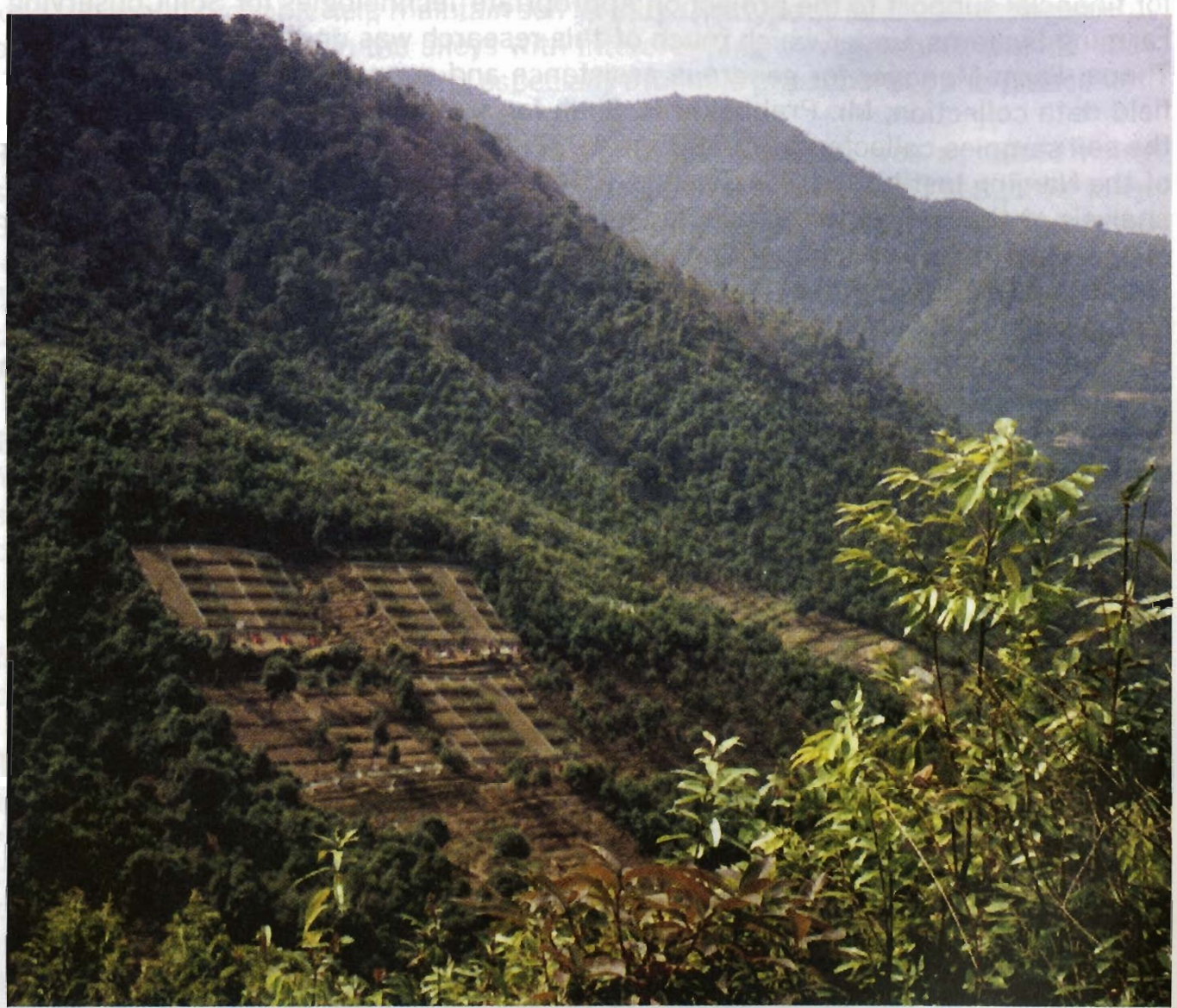

View of ICIMOD's Demonstration and Training Centre, Godavari, in 1997 showing the replicate soil erosion plots (four treatments with hedgerows and one control without hedgerows) and other nitrogen-fixing hedgerow terraces. 


\section{contents}

Foreword - Focus on Godavari

Preface

Executive Summary

Acknowledgements

Acronyms and Abbreviations

Chapter 1: Erosion and Degradation of Sloping Agricultural

Land and Technologies for Mitigation

- Tang Ya and A. Beatrice Murray

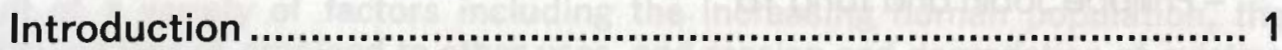

Sloping Agricultural Land Technology ....................................... 2

SALT Trials at the Godavari Demonstration and Training Centre. 3

Results and Conclusions ............................................................ 6

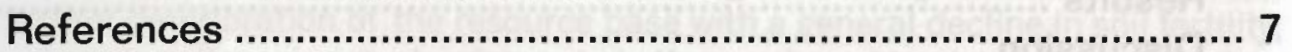

Chapter 2: Effect of Contour Hedgerows of Nitrogen-Fixing

Plants on Soil Erosion of Sloping Agricultural Land ..................... 9

- Tang Ya and Gopal Nakarmi ...............................................................................

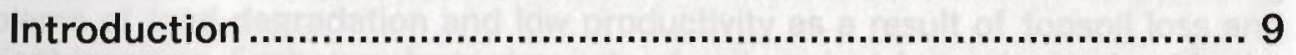

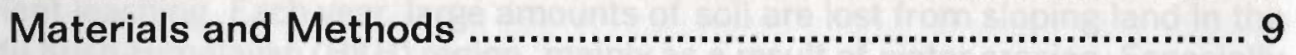

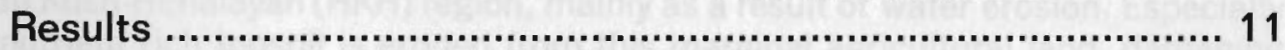

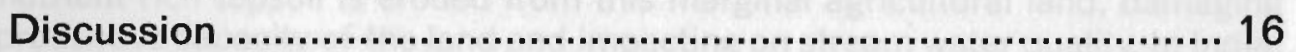

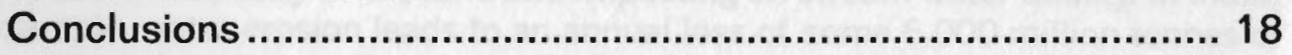

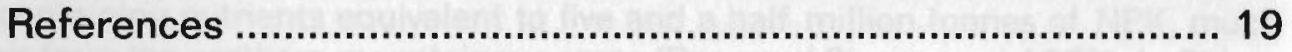

Chapter 3: Changes in Soil Fertility of Sloping Agricultural

Land with Contour Hedgerows of Nitrogen-fixing Plants ............ 21

- Tang Ya

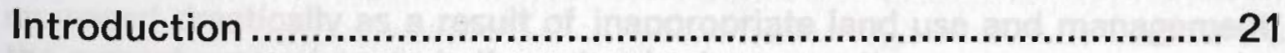

Materials and Methods ........................................................ 22

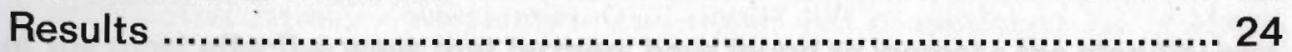

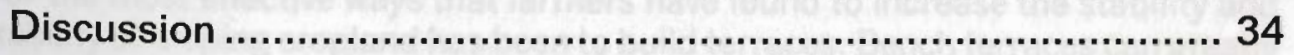

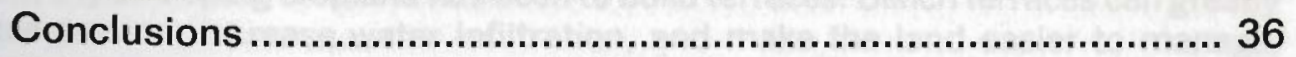

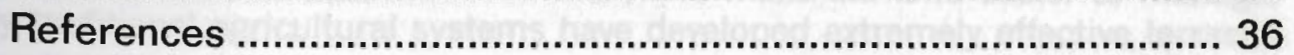


Chapter 4: Nutrient Competition Between Hedgerows and Crops in a Contour Hedgerow Intercropping System

- Tang Ya

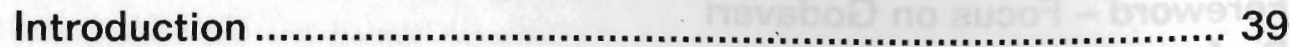

Materials and Methods ........................................................ 40

Results ............................................................................... 41

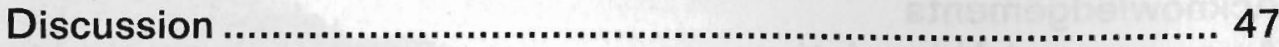

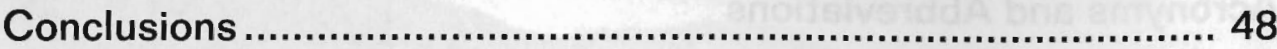

References ................................................................... 48

Chapter 5: Competition for Soil Moisture Between Hedgerows and Crops in a Contour Hedgerow Intercropping System

- Philippe Jobin and Tang Ya

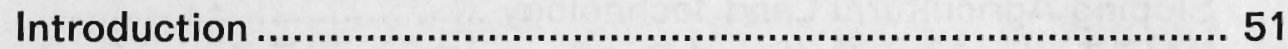

Material and Methods ........................................................ 52

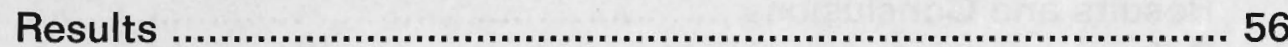

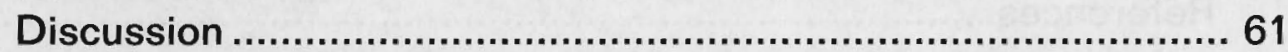

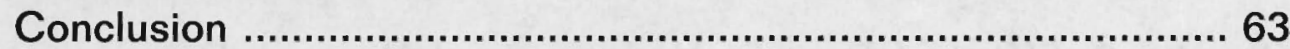

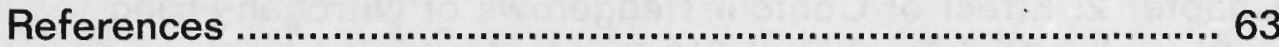

